\title{
Combining Sun-Induced Chlorophyll Fluorescence and Photochemical Reflectance Index Improves Diurnal Modeling of Gross Primary Productivity
}

\author{
Anke Schickling ${ }^{1,+}{ }^{\dagger}$ Maria Matveeva ${ }^{1,+}$, Alexander Damm ${ }^{2,+}{ }^{+}$Jan H. Schween ${ }^{3}$, \\ Andreas Wahner ${ }^{4}$, Alexander Graf ${ }^{5}$, Susanne Crewell ${ }^{3}$ and Uwe Rascher ${ }^{1, *}$ \\ 1 Institute of Bio- and Geosciences, IBG-2: Plant Sciences, Forschungszentrum Jülich GmbH, \\ Wilhelm-Johnen Straße, Jülich 52428, Germany; a.schickling@fz-juelich.de (A.S.); \\ m.matveeva@fz-juelich.de (M.M.) \\ 2 Remote Sensing Laboratories, University of Zurich, Winterthurerstrasse 190, Zurich 8057, Switzerland; \\ adamm@geo.uzh.ch \\ 3 Institute of Geophysics and Meteorology, University of Cologne, Zülpicher Str. 49, Köln 50674, Germany; \\ jschween@uni-koeln.de (J.H.S.); crewell@meteo.uni-koeln.de (S.C.) \\ 4 Institute of Energy and Climate Research, IEK-8: Troposphere, Forschungszentrum Jülich GmbH, \\ Wilhelm-Johnen Straße, Jülich 52428, Germany; a.wahner@fz-juelich.de \\ 5 Institute of Bio- and Geosciences, IBG-3: Agrosphere, Forschungszentrum Jülich GmbH, \\ Wilhelm-Johnen Straße, Jülich 52428, Germany; a.graf@fz-juelich.de \\ * Correspondence: u.rascher@fz-juelich.de; Tel.: +49-2461-61-2638; Fax: +49-2461-61-2492 \\ + These authors contributed equally to this work.
}

Academic Editors: Jose Moreno and Prasad S. Thenkabail

Received: 14 February 2016; Accepted: 30 June 2016; Published: 8 July 2016

\begin{abstract}
Sun-induced chlorophyll fluorescence (F) is a novel remote sensing parameter providing an estimate of actual photosynthetic rates. A combination of this new observable and Monteith's light use efficiency (LUE) concept was suggested for an advanced modeling of gross primary productivity (GPP). In this demonstration study, we evaluate the potential of both $\mathrm{F}$ and the more commonly used photochemical reflectance index (PRI) to approximate the LUE term in Monteith's equation and eventually improve the forward modeling of GPP diurnals. Both F and the PRI were derived from ground and airborne based spectrometer measurements over two different crops. We demonstrate that approximating dynamic changes of LUE using F and PRI significantly improves the forward modeling of GPP diurnals. Especially in sugar beet, a changing photosynthetic efficiency during the day was traceable with $\mathrm{F}$ and incorporating $\mathrm{F}$ in the forward modeling significantly improved the estimation of GPP. Airborne data were projected to produce F and PRI maps for winter wheat and sugar beet fields over the course of one day. We detected a significant variability of both, F and the PRI within one field and particularly between fields. The variability of F and PRI was higher in sugar beet, which also showed a physiological down-regulation of leaf photosynthesis. Our results underline the potential of $\mathrm{F}$ to serve as a superior indicator for the actual efficiency of the photosynthetic machinery, which is linked to physiological responses of vegetation.
\end{abstract}

Keywords: spectroscopy; sun-induced chlorophyll fluorescence; $\mathrm{F}_{760}$; gross primary productivity; GPP; vegetation; photosynthesis; PRI

\section{Introduction}

Photosynthetic $\mathrm{CO}_{2}$ uptake in terrestrial vegetation ecosystems mediated by plant photosynthesis is commonly referred to as gross primary production (GPP) and constitutes the largest flux of the global carbon cycle [1,2]. Variations in photosynthetic carbon fixation are identified as the main 
sources of terrestrial carbon cycle dynamics [2]. GPP accounts for approximately 120 Gt C per year, which is 15 times higher than the global carbon production from combustion of fossil fuels in human industrial processes [1]. This means that even relatively small changes in the terrestrial photosynthetic carbon fixation may lead to significant deviations and uncertainties in estimating regional and global carbon fluxes. This spatio-temporal variability of ecosystem photosynthesis is not sufficiently understood yet, as GPP is determined by complex processes related to plant phenology and physiological activities [2]. Therefore, substantial efforts are being undertaken to better measure this process and eventually provide more precise constrains for mechanistic carbon models which are frequently used to predict GPP.

Different modeling strategies can be applied to describe how solar irradiance is converted into dry matter via photosynthesis [3]. However, most models include the light-use-efficiency (LUE) approach according to $[4,5]$ where GPP is expressed as a product of incident photosynthetically active solar radiation (PAR), its absorbed fraction $\left(f_{\text {APAR }}\right)$, and an efficiency term for conversion of absorbed energy into carbon fixation. This latter term is usually called LUE. In modeling approaches, a maximum LUE for each Plant Functional Type (PFT) is assumed that is down regulated by environmental parameters. In plant sciences, however, it is well established that photosynthetic light conversion represents a complex biophysical and biochemical process, which is influenced by a variety of environmental factors, depends on the ontogeny of the single plant, and is ruled by the genetic plasticity of a particular species or variety [6]. Moreover, the environmental conditions of our planet are being altered by, for example, greatly increasing the amount of biologically available nitrogen resources via artificial fertilizer and replacing natural plant ecosystems by managed vegetation consisting of new species and their compositions. Therefore, modern agricultural crops may appear to have fundamentally different photosynthetic characteristics than naturally evolved species. As a result, it is unclear how precise current modeling assumptions are for predicting future photosynthetic carbon uptake by terrestrial vegetation.

GPP rates cannot be measured directly and precisely using remote sensing (RS) approaches. Available RS approaches rely on the measurement of vegetation greenness which is related to the amount of the photosynthetic active pigment chlorophyll, thus, being sensitive to potential photosynthesis only. There have been some attempts to exploit small reflectance changes around $531 \mathrm{~nm}$ due to xanthophyll pigment changes to quantify photosynthetic efficiency [7]. The resulting photochemical reflectance index (PRI), however, was developed at the leaf level [8] and is known to be largely affected by the structure of the canopy [9], pigment pool sizes [10] and illumination effects [11,12]. Nevertheless, the PRI is currently applied to ecosystem and it remains an open debate whether or not canopy-level processes can be quantified by such RS approaches [13].

A novel RS approach recently suggested to advance estimates of GPP is the sun-induced chlorophyll fluorescence signal (F). The weak fluorescence signal emitted from the cores of the two photosystems can be detected passively across scales [14] using high-resolution spectrometers in combination with the Fraunhofer line depth (FLD) principle [15]. Currently, the European Space Agency (ESA) is evaluating this new RS approach in the framework of the ESA Earth Explorer 8 program through the Fluorescence Explorer (FLEX) mission (http:/ / www.esa.int/ESA). Several studies are underway to evaluate the technical feasibility of measuring the two-peak fluorescence signals at $687 \mathrm{~nm}$ and $760 \mathrm{~nm}\left(\mathrm{~F}_{687}\right.$ and $\left.\mathrm{F}_{760}\right)$ from a spaceborne platform. Additionally, it became recently possible to use spectrometers on board the GOSAT (TANSO-FTS) and the MetOp (GOME-2) satellites to derive $F$ at a single waveband in coarse spatial and temporal resolution [16-19].

In the last decade several studies have investigated the potential of $\mathrm{F}_{760}$ as an estimate of GPP. For example, diurnal GPP estimation of a corn field was improved when including $\mathrm{F}$ as a proxy for LUE [20]; however, no relationship between PRI and LUE was found. Additional studies in corn, however, showed that GPP estimation could be significantly improved by incorporating both PRI and $F$ [21], which is in agreement with studies from different agricultural crops and grassland [22,23]. In this paper, we exploit the capability to measure diurnal courses of $\mathrm{F}$ at $760 \mathrm{~nm}\left(\mathrm{~F}_{760}\right)$ and PRI 
using ground and airborne based spectroscopy. We investigate spatial heterogeneity of $F$ and the PRI within crop fields, in-between field of two different agricultural species, winter wheat and sugar beet. Further, we evaluate the improvement of diurnal GPP modeling using F and PRI in combination with Monteith's LUE approach for the test case of those two species.

\section{Materials and Methods}

\subsection{Study Site}

The study site is located in an agricultural area within the Rur catchment (North Rhine-Westphalia, Germany), dominated by cereals and sugar beet with scattered occurrences of rapeseed and corn. The two main test fields are a winter wheat field (Triticum aestivum L.) near the village of Selhausen $\left(50^{\circ} 52^{\prime} 12^{\prime \prime} \mathrm{N}, 6^{\circ} 26^{\prime} 59^{\prime \prime} \mathrm{E}, 105 \mathrm{~m}\right.$ a.s.1.) and a sugar beet field (Beta vulgaris L.) near the village of Merken $\left(50^{\circ} 50^{\prime} 46^{\prime \prime} \mathrm{N}, 6^{\circ} 23^{\prime} 48^{\prime \prime} \mathrm{E}, 114 \mathrm{~m}\right.$ a.s.1.).

The core measurements were performed on five days in 2008 that were chosen based on the phenological status of the crops as well as on weather conditions. Winter wheat was measured at different growth stages in spring and summer on DOY 127 (Day of Year 127; 6 May 2008) and on DOY 176 (24 June 2008). On DOY 127, winter wheat plants had already developed three nodes. On DOY 176, the flowering period of winter wheat was over and the ears were already fully developed but still green. Sugar beet measurements were performed on DOY 183 (1 July 2008) and DOY 253 (9 September 2008). By DOY 183, more than nine leaves of the sugar beet plants had developed, and on DOY 253, the canopy was nearly closed.

\subsection{Leaf-Level Measurements of the Photosynthetic Carbon Uptake Rate and Stomatal Conductance}

$\mathrm{CO}_{2}$ and water exchange processes between the vegetation and atmosphere were characterized at different scales. Gas exchange measurements at the leaf level represent the net photosynthetic $\mathrm{CO}_{2}$ uptake rate and transpiration rates of different individual leaves within the canopy. These measurements were complemented at the canopy level by eddy covariance (EC) tower measurements, representing exchange processes of the entire field.

Leaf-level gas exchange was measured using the Li-COR 6400 portable photosynthesis system (Li-COR, Lincoln, NE, USA). The $\mathrm{CO}_{2}$ level of the inlet air was maintained in a steady state at $390 \mathrm{ppm}$. The light response curves of the net photosynthetic $\mathrm{CO}_{2}$ uptake rate $(\mathrm{A})$ and the stomatal resistance (rs) $[24,25]$ were measured in the field using an artificial light source of the manufacturer. These measurements were performed at photosynthetic photon flux density (PPFD) levels of 2000, $1000,500,200,100,50,20,10 \mu \mathrm{mol} \mathrm{m}{ }^{-2} \cdot \mathrm{s}^{-1}$ and in dark conditions. Most measurement protocols for gas exchange measurements with the Li-COR 6400 refer to laboratory measurements starting the light response curves in the dark adapted state. Under field conditions, plants are already in a light-adapted state and must be dark regulated for at least $30 \mathrm{~min}$ for light curves. To minimize the waiting time between individual measurements, the light curves were started at $2000 \mu \mathrm{mol} \mathrm{m}{ }^{-2} \cdot \mathrm{s}^{-1}$ and were then down regulated to dark adaptation. Air humidity and temperature inside the assimilation chamber were adjusted to ambient conditions. Determination of a single light response curve took approximately $45 \mathrm{~min}$; therefore, up to twelve measurements of one leaf per individual plant could be performed between 07:00 and 16:00 UTC on each observation day. On DOY 127, fully developed leaves from the upper vegetation layer of winter wheat were taken for gas exchange measurements. On DOY 176, since leaves in lower canopy layers had already started senescence, the flag leaf, which is the uppermost leaf on the tern, was used for the measurements. For sugar beet, mature leaves were present on all days, and the gas exchange measurements were performed on randomly selected mature leaves of the external ring of the sugar beet rosette.

To characterize the potential photosynthetic performance of different plants during the day, the maximum net photosynthetic $\mathrm{CO}_{2}$ uptake rate $\left(\mathrm{A}_{\max }\right)$ and the maximum stomatal resistance $\left(\mathrm{rs}_{\max }\right)$ were estimated from each light response curve of gas exchange measurements using a single 
exponential fit (Figure S1 supplementary materials). In case the leaves did not adapt fast enough to the high light conditions, rs data were excluded from the dataset.

\subsection{Measurements of Canopy-Scale Carbon Fluxes (Eddy Covariance)}

Eddy-covariance (EC, [26]) stations were operated in the center of two representative fields, one each for wheat and sugar beet to provide canopy-scale net $\mathrm{CO}_{2}$ and water vapor fluxes. The core EC instrumentation consisted of a CSAT3 sonic anemometer (Campbell Scientific, Logan, UT, USA) and a Li7500 open-path gas analyzer (Li-COR, Lincoln, NE, USA), both logged at a frequency of $20 \mathrm{~Hz}$ and mounted 1.5-2 m. Covariances and net $\mathrm{CO}_{2}$ fluxes were computed over half-hourly time intervals using the software packages TK2 [27] and ECpack [28]. Detailed descriptions of the measurements and data processing are given in $[29,30]$.

Derivation of $\mathrm{GPP}_{\mathrm{EC}}$ from net $\mathrm{CO}_{2}$ fluxes and smoothing were performed as described in [20], using the flux partitioning tool [31]. Actual photosynthetic light-use efficiency (LUEEC) was derived as the ratio of $\mathrm{GPP}_{\mathrm{EC}}$ and absorbed photosynthetically active radiation (APAR) obtained from spectroradiometric measurements (see Section 2.6).

\subsection{Spectroradiometric Measurements on the Ground}

Spectroradiometric ground data were acquired using an ASD FieldSpec III spectroradiometer (ASD Inc., Boulder, CO, USA) which measures radiances with $3 \mathrm{~nm}$ full-width-half-maximum (FWHM) over the wavelength range from $350 \mathrm{~nm}$ to $1050 \mathrm{~nm}$. The instrument has a spectral sampling interval of $1.4 \mathrm{~nm}$ and a signal-to-noise ratio (SNR) of 4000. The integration time of the sensor was adjusted manually to the incident light conditions to avoid signal saturation and enable sufficient SNR. The field of view of the fiber optic is about $25^{\circ}$.

Spectroradiometric measurements were performed from 07:00 to 16:00 UTC on each observation day. The fiber optic was installed on a robotic arm of $60 \mathrm{~cm}$ length at approximately $1.50 \mathrm{~m}$ above the canopy. Vegetation height depended on field and measurement date and was $43 \mathrm{~cm}$ on DOY $127,77 \mathrm{~cm}$ on DOY 176, $47 \mathrm{~cm}$ on DOY 183, and $63 \mathrm{~cm}$ on DOY 253. Consecutive scans of four different areas of the field were performed, interrupted by measurements of a Spectralon ${ }^{\mathrm{TM}}$ white reference panel (WR) $(25 \mathrm{~cm} \times 25 \mathrm{~cm})$ (Labsphere, North Sutton, NH, USA), similar to the protocol described in [20]. One measurement cycle took roughly six minutes. For each position, 10 spectra were recorded, each representing an average of 25 individual spectra automatically integrated by the spectroradiometer. For the subsequent analyses, only measurements not affected by any kinds of errors and changes in atmospheric conditions were used. Vegetation indices were calculated from the reflectance of the observed surface given by the ratio of the radiance spectra above the vegetation surface and the radiance above the WR panel.

\subsection{Spectroradiometric Measurements with the Dimona Aircraft}

On two days (DOY 176 and 183), the research aircraft ECO-Dimona from Metair AG (Menzingen, Switzerland) was flying on straight legs at approximately $250 \mathrm{~m}$ above the study site [32]. The flight pattern aimed at aligning most of the legs parallel and perpendicular to the largest extent of the main fields (Figure 1). The crossing of both legs was above the main fields of winter wheat on DOY 176 (Figure 1B) and of sugar beet on DOY 183 (Figure 1A). The aircraft flew over the winter wheat field 46 times, between 11:15 and 15:15 UTC and over the sugar beet field 68 times between 7:30 and 10:30 UTC in the morning and 11:30 to 15:30 UTC in the afternoon. 


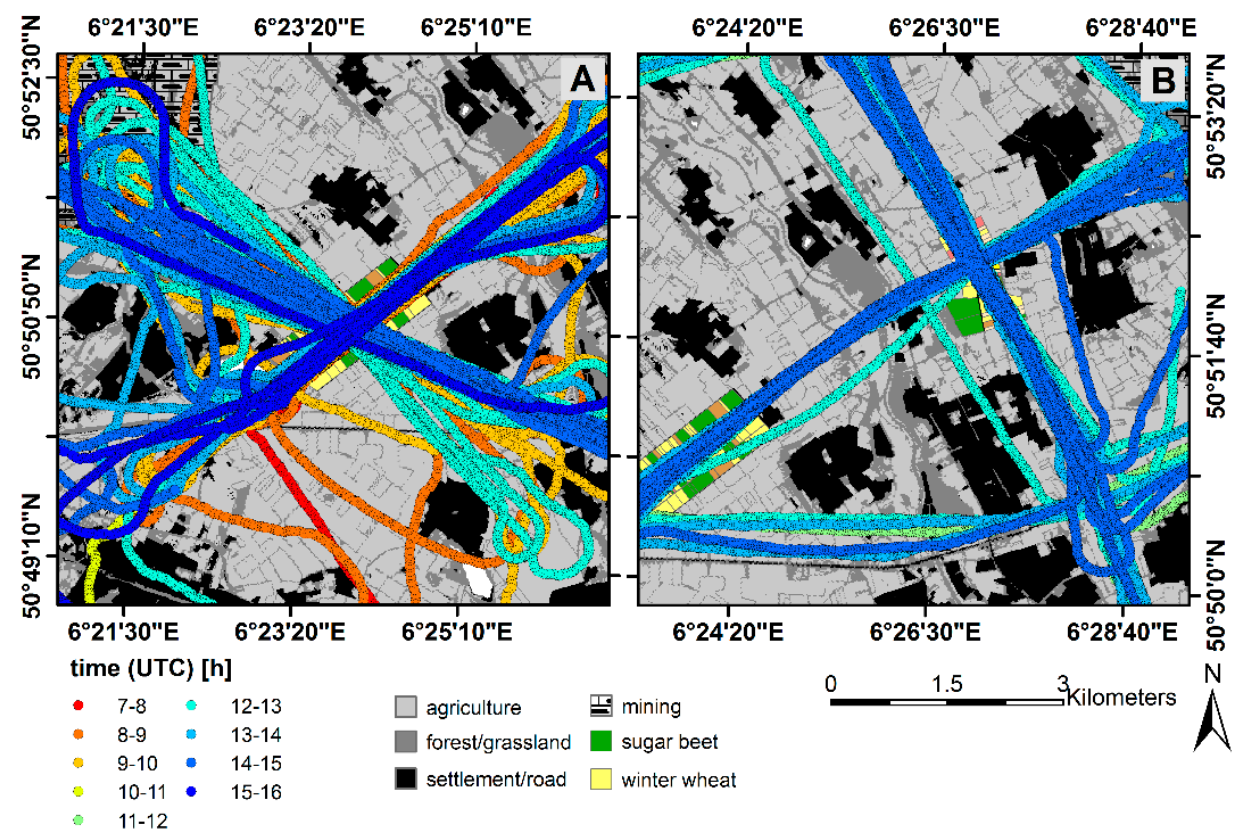

Figure 1. Flight pattern on both observation days: (A) Sugar beet field in Merken (DOY 183), overflown 68 times, at 7:30-10:30 UTC and 11:30-15:30 UTC; (B) winter wheat field in Selhausen (DOY 176), overflown 46 times at 11:15-15:15 UTC. The color indicates the time of measurements.

A calibrated field spectrometer (FieldSpec Pro, ASD Inc., Boulder, CO, USA) was mounted in one of the under-wing pods of the DIMONA research aircraft. Radiance measurements were captured in Nadir orientation with a $1^{\circ}$ fiber optic over the wavelength range between $350 \mathrm{~nm}$ and $1050 \mathrm{~nm}$ with a FWHM of $3 \mathrm{~nm}$. The light beam was integrated for $130 \mathrm{~ms}$. Three spectra were averaged to increase SNR. The relatively small field of view in combination with the relatively slow and low flying aircraft resulted in a surface area of $4 \mathrm{~m} \times 20 \mathrm{~m}$ represented in one averaged spectrum. The instrument was operated in continuous mode, and spectra were collected with approximately $2 \mathrm{~Hz}$. A trigger signal by the FieldSpec was used to record the exact time of each radiance measurement in the central data acquisition system of the aircraft and to capture a video image ( $640 \times 480$ pixels, 12-bit, gray values) using an industrial video camera (Flea, Point Grey Research, Vancouver, BC, Canada; with a $25 \mathrm{~mm}$ Cosmicar/Pentax lens) having a 10.5 degree field of view.

The spatial position of the radiance measurement was computed from the position and orientation of the aircraft (logged by a TANS vector phase sensitive GPS system blended with a 3-axis accelerometer; [32]), the height above ground, and a digital elevation model. We evaluated the geometric accuracy using numerous characteristic scenes from video images and obtained an actual geometric error of less than $5 \mathrm{~m}$.

We compensated atmospheric disturbances present in the at-sensor radiance measurements and calculated hemispherical-conical reflectance factors (HCRF) using atmospheric parameters (i.e., surface irradiance, atmospheric transmittance, path scattered radiance, spherical albedo) calculated with the radiative transfer model MODTRAN5 [33]. The obtained atmospheric parameters were spectrally resampled based on the sensor characteristics.

\subsection{Parameters Derived from Spectroradiometric Measurements}

$\mathrm{F}$ at $760 \mathrm{~nm}\left(\mathrm{~F}_{760}\right)$ was retrieved from ground and airborne radiance measurements using the 3FLD approach described in detail in [34]. In short, the retrieval method uses the wide $\mathrm{O}_{2}-\mathrm{A}$ absorption band to decouple the emitted fluorescence radiance from the reflected radiance by using two radiance measurements, $L_{i}$ inside (i, $760 \mathrm{~nm}$ ) and $L_{o}$ outside (o) of the $\mathrm{O}_{2}$-A band. They can be expressed as: 


$$
L_{j}=L_{j}^{p}+\frac{\left(E_{j}^{g} \frac{\rho_{j}}{\pi}+F_{j}\right) \tau \uparrow_{j}}{1-S_{j} \cdot \rho_{j}}, j=i, o
$$

where $L^{p}$ is the path scattered radiance, $E^{g}$ is the global irradiance (including direct and diffuse irradiance components) arriving on the surface, $\rho$ is the surface reflectance, $\tau \uparrow$ is the upwelling transmittance, and $S$ is the spherical albedo. The atmospheric variables were calculated for each individual observation with MODTRAN5 (i.e., $L^{p}, E^{g}, \tau \uparrow, S$ ). Reducing the number of unknowns (i.e., $\rho_{i}, \rho_{o}, F_{i}, F_{o}$ ) to only two is needed to eventually solve the system of equations (Equation (1)). We therefore used the 3FLD approach [35] and linearly related $\rho$ and $F$ inside and outside of the $\mathrm{O}_{2}$-A band. With this, $F_{760}$ can be retrieved as:

$$
\begin{aligned}
& F_{760}=F_{i}=B\left[\frac{X_{i}\left(E_{o}^{*}+X_{o} \cdot S_{o}\right)-A X_{o}\left(E_{i}^{*}+X_{i} \cdot S_{i}\right)}{B\left(E_{o}^{*}+X_{o} \cdot S_{o}\right)-A\left(E_{i}^{*}+X_{i} \cdot S_{i}\right)}\right] \text {, with } \\
& X_{j}=\frac{\left(L_{j}-L_{j}^{p}\right)}{\tau \uparrow j}, E_{j}^{*}=\frac{E_{j}^{g}}{\pi} j=i, o \text {, and } \\
& \left.\begin{array}{rl}
\rho_{i} & =A \rho_{o} \\
F_{i} & =B F_{o}
\end{array}\right\}
\end{aligned}
$$

$X_{j}$ equals the top-of canopy (ToC) radiance leaving the surface. $A$ is the factor relating $\rho_{i}$, and $\rho_{o}$ and was derived from linear interpolation of $\rho$ using the left $(753 \mathrm{~nm})$ and right $(771 \mathrm{~nm}) \mathrm{O}_{2}$-A band shoulders with:

$$
\begin{gathered}
A=\frac{\rho_{753} \omega_{1}+\rho_{771} \omega_{2}}{\rho_{753}} \\
\omega_{1}=\frac{771-760}{771-753} \text {, and } \omega_{2}=\frac{760-753}{771-753}
\end{gathered}
$$

$B$ is a factor relating $\mathrm{F}$ inside and outside the $\mathrm{O}_{2}-\mathrm{A}$ band and was fixed to a value of 0.8 , justified by simulations and experiments. Since the product of $S$ and $\rho$ (Equation (1)) can be assumed as $<<1$, $S$ was eventually set to zero for the F retrieval. Further, slight uncertainties of the atmospheric modeling and remaining spectral shift artifacts can cause uncertainties in F retrievals. We therefore applied a semi-empirical correction coefficient derived over non-fluorescence targets to account for such inaccuracies and to increase the precision of F retrievals (see [34] for a detailed description of this approach).

For the retrieval of $\mathrm{F}_{760}$ from ground measurements, $E^{g}$ was determined with a measurement of the reference panel. Further, we assumed $L^{p}=0$ and $\tau \uparrow=1$, justified by the short distance between surface and sensor $(1 \mathrm{~m})$.

The yield of $\mathrm{F}_{760}\left(\mathrm{~F}_{760 \text {-yield }}\right)$ is theoretically related to the LUE and is calculated by dividing $\mathrm{F}_{760}$ by the light absorbed by the green plant material $\left(\mathrm{APAR}_{\text {green }}\right)$ :

$$
\mathrm{F}_{760-\text { yield }}=\frac{\mathrm{F}_{760}}{\mathrm{APAR}}
$$

In this study, we estimated APAR as the integrated difference between the WR radiance signal and the radiance measure over the vegetation canopy over the wavelength range of $400-700 \mathrm{~nm}$. According to [36], APAR calculated this way corresponds to the PAR radiation absorbed by the entire canopy including photosynthetic vegetation (PV) and non-photosynthetic active vegetation (NPV). We consider uncertainties caused by NPV is less influential for the reliability of our results, since we expect almost no variation of NPV-PV fractions over the course of one day. However, this variation is important for seasonal studies. 
In addition to the fluorescence parameters, the PRI was calculated according to [8]. The PRI is a relative measure of the actual (de-)epoxidation state of xanthophylls. Theoretically, PRI values can vary between -1 and 1 with lower values presenting an activation of non-photochemical energy dissipation (NPQ). To facilitate an easier inclusion of the PRI in our modeling framework, PRI values were linearly scaled to values ranging around 0.5 and calculated as:

$$
\mathrm{PRI}=\frac{1}{2}\left[\frac{\rho_{531}-\rho_{570}}{\rho_{531}+\rho_{570}}\right]+1
$$

where $\rho_{531}$ is the reflectance at $531 \mathrm{~nm}$, which is strongly affected by the de-epoxidation of violaxanthin to zeaxanthin, and $\rho_{570}$ is the reflectance at the reference wavelength of $570 \mathrm{~nm}$ unaffected by the de-epoxidation state.

The normalized difference vegetation index (NDVI) is strongly correlated with the canopy chlorophyll content $[37,38]$ and was used as a proxy of the amount of vegetation that is intercepting radiation. NDVI was derived as:

$$
\mathrm{NDVI}=\frac{\rho_{780-785}-\rho_{680-685}}{\rho_{780-785}+\rho_{680-685}}
$$

where $\rho_{680-685}$ represents the mean reflectance value in the red spectral domain between $680 \mathrm{~nm}$ and $685 \mathrm{~nm}$ and $\rho_{780-785}$ is the mean reflectance value in the near infrared spectral domain between $780 \mathrm{~nm}$ and $785 \mathrm{~nm}$.

\subsection{Forward Modeling of Gross Primary Productivity}

In the following we use Monteith's LUE concept [4,5] to calculate GPP. We postulate that the fraction of absorbed light $\left(f_{\text {APAR }}\right)$ and the efficiency of the photosynthetic apparatus (LUE) can be determined from the remotely sensed parameters NDVI, F 760 -yield, and the PRI:

(A) $\mathrm{GPP}_{\mathrm{A}}$ describes the classical approach where LUE is considered to remain constant over the course of the day. Thus LUE is parameterized as an optimized but constant value for each diurnal course. We measured $f_{\text {APAR }}$ and PAR directly using the spectroradiometer on the ground.

$$
\mathrm{GPP}_{\mathrm{A}}=\mathrm{LUE}_{\text {const }} \cdot f_{\mathrm{APAR}} \cdot \operatorname{PAR}\left[\mu \mathrm{mol} \cdot \mathrm{m}^{-2} \cdot \mathrm{s}^{-1}\right]
$$

(B) It has been described in the literature that the NDVI of the observed surface can be used as proxy for $f_{\mathrm{APAR}}$ in the canopy [39]. Consequently, approach $\mathrm{GPP}_{\mathrm{B}}$ was formulated by using NDVI as a proxy for $f_{\text {APAR }}$ in $\mathrm{GPP}_{\mathrm{A}}$, aiming to estimate GPP solely from spectroscopic measurements, while using a constant LUE as for GPP . The LUE $_{\text {const }}$ is the daytime mean (07-16 UTC) of the LUE measured with the EC method. The parameters $\mathrm{m}$ and $\mathrm{k}$ were obtained from the slope and axis interception of the linear fit between $f_{\mathrm{APAR}}$ and NDVI. The parameters of the linear fit can be found in Table S1 in the supplemental materials.

$$
\mathrm{GPP}_{\mathrm{B}}=\mathrm{LUE}_{\text {const }} \cdot(\mathrm{m} \cdot \mathrm{NDVI}+\mathrm{k}) \cdot \operatorname{PAR}\left[\mu \mathrm{mol} \cdot \mathrm{m}^{-2} \cdot \mathrm{s}^{-1}\right]
$$

As we will show later (see Section 3.5), approaches $\mathrm{GPP}_{\mathrm{A}}$ and $\mathrm{GPP}_{\mathrm{B}}$ performed equally well for all five observation days. Therefore, NDVI scaling for $f_{\text {APAR }}$ as in $\mathrm{GPP}_{\mathrm{B}}$ was also used in the remaining approaches. For those three approaches LUE is also parameterized linearly using the variables $\mathrm{F}_{760 \text {-yield }}$ and PRI.

(C) GPP $_{C}$ describes the approach where LUE is considered to be parameterized linearly using the

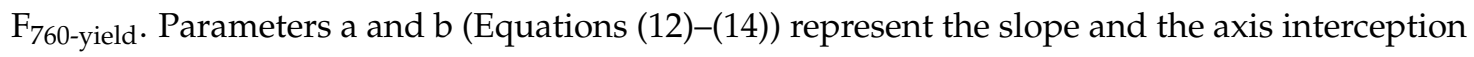
of the linear fit between LUE measured with the EC method and each remote sensed parameter. The parameters of the linear fits can be found in Tables S2-S4 in the supplemental materials. 


$$
\operatorname{GPP}_{\mathrm{C}}=\left(\mathrm{a}_{1} \cdot F_{760-\text { yield }}+\mathrm{b}_{1}\right) \cdot(\mathrm{m} \cdot \mathrm{NDVI}+\mathrm{k}) \cdot \operatorname{PAR}\left[\mu \mathrm{mol} \cdot \mathrm{m}^{-2} \cdot \mathrm{s}^{-1}\right]
$$

(D) Another approach, where LUE is considered to be parameterized linearly to PRI, could be written as follows:

$$
\operatorname{GPP}_{\mathrm{D}}=\left(\mathrm{a}_{2} \cdot P R I+\mathrm{b}_{2}\right) \cdot(\mathrm{m} \cdot \mathrm{NDVI}+\mathrm{k}) \cdot \operatorname{PAR}\left[\mu \mathrm{mol} \cdot \mathrm{m}^{-2} \cdot \mathrm{s}^{-1}\right]
$$

(E) To include both the non-photochemical energy dissipation (NPQ) and the efficiency of photochemical energy separation in the LUE concept, a linear relation to the product of both parameters, $P R I$ and $F_{760}$-yield, is used:

$$
\operatorname{GPP}_{\mathrm{E}}=\left(\mathrm{a}_{3} \cdot\left(F_{760-\text { yield }} \cdot P R I\right)+\mathrm{b}_{3}\right) \cdot(\mathrm{m} \cdot \mathrm{NDVI}+\mathrm{k}) \cdot \operatorname{PAR}\left[\mu \mathrm{mol} \cdot \mathrm{m}^{-2} \cdot \mathrm{s}^{-1}\right]
$$

\section{Results}

\subsection{Spatial and Temporal Variability of Optical Parameters in Winter Wheat}

The spatial variation of $\mathrm{F}_{760}$ and PRI over winter wheat fields is shown in Figure 2. Part of the variability of $F_{760}$ visible in Figure 2 is due to temporal dependence of $F_{760}$ on changing APAR conditions, with highest values closest to solar noon. Further a clear difference of $\mathrm{F}_{760}$ between fields is obvious for both sites, likely caused by different breeding varieties, field management practices, soil types, the sowing date, dates of fertilization, and plant disease treatment.

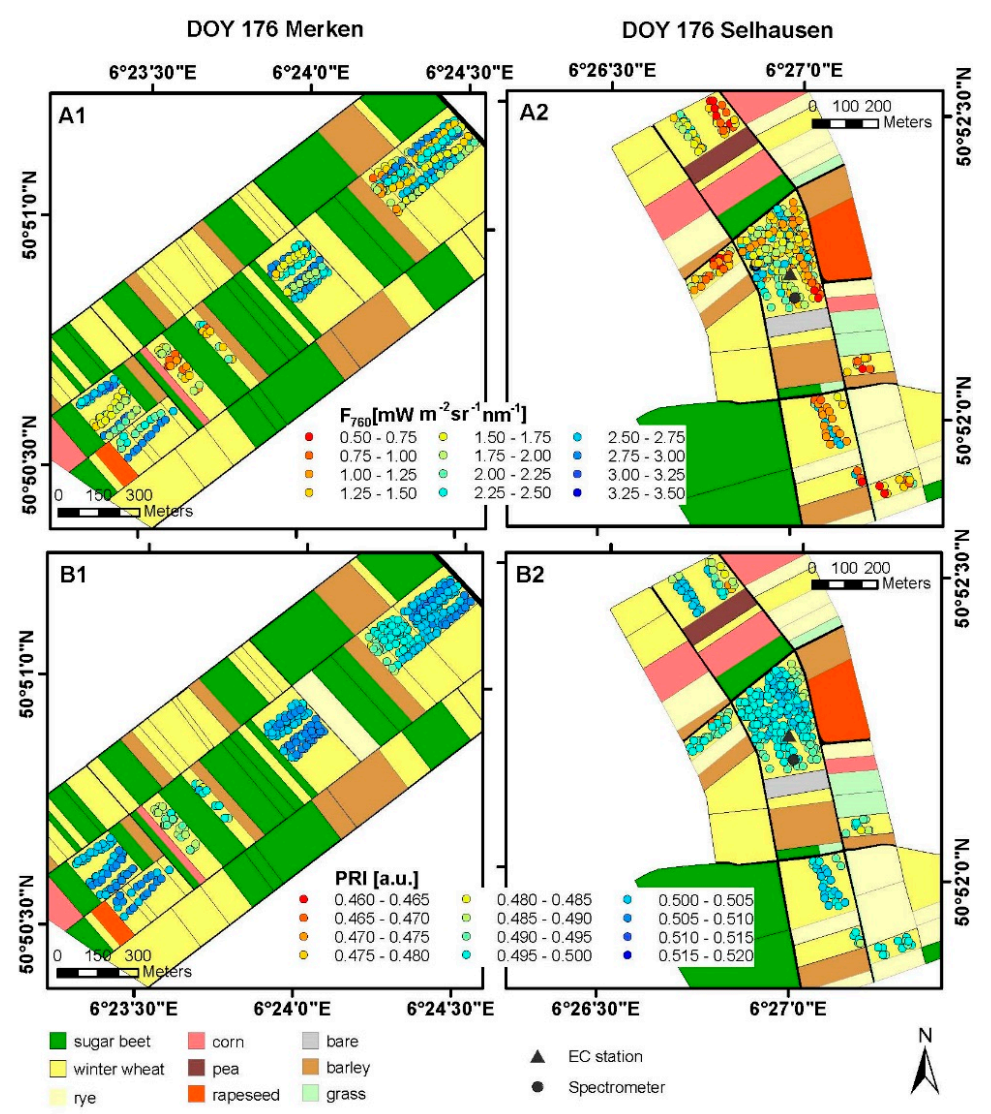

Figure 2. Airborne based $F_{760}$ and PRI measurements acquired on DOY 176 (24 June 2008) over winter wheat (colored circles) superimposed over a land cover map. Left column: fields close to Merken. Right column: fields close to Selhausen. Top row (A1,A2): Sun-induced chlorophyll fluorescence at $760 \mathrm{~nm}\left(\mathrm{~F}_{760}\right)$. Bottom row (B1,B2): Photochemical reflectance index (PRI). Black triangle and dot mark the location of the ground observations. 
The spatial distribution of PRI values is more homogeneous compared to $\mathrm{F}_{760}$. For PRI we detected no variations related to the time of day or APAR and no between-field variations.

\subsection{Spatial and Temporal Variability of Optical Parameters in Sugar Beet}

The spatial distribution of $\mathrm{F}_{760}$ and PRI in sugar beet fields is shown in Figure 3. Data are divided in measurements before and after solar noon and only using comparable incoming PAR values (i.e., $210-290 \mathrm{~W} \cdot \mathrm{m}^{-2}$ ). $\mathrm{F}_{760}$ values were higher in the morning than in the afternoon despite comparable irradiance levels. In contrast, PRI values were higher in the afternoon (Figure 3).

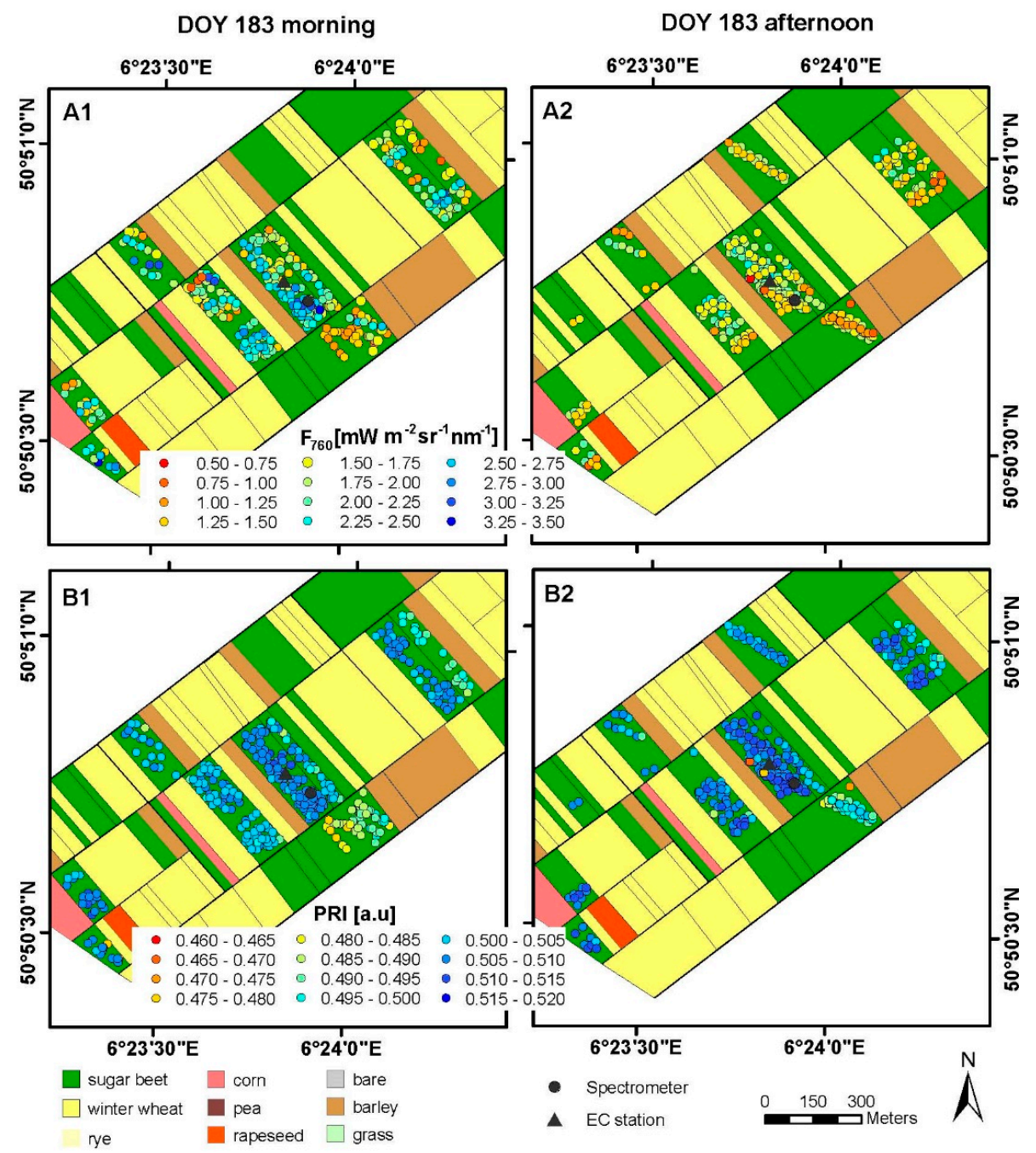

Figure 3. Airborne based $F_{760}$ and PRI measurements acquired on DOY 183 (1 July 2008) over sugar beet (colored circles) superimposed over a land cover map. Left column: measurements taken before solar noon. Right column: measurements taken after solar noon. Top row (A1,A2): Sun-induced fluorescence at $760 \mathrm{~nm}\left(\mathrm{~F}_{760}\right)$. Bottom row (B1,B2): Photochemical reflectance index (PRI). Black triangle and dot mark the location of the ground observations.

\subsection{Results of Spectroradiometric and Eddy Covariance Measurements on the Ground}

To illustrate the temporal behavior, the diurnal courses of APAR, GPP and several other parameters are shown in Figure $4 . \mathrm{F}_{760}$ values show a distinct diurnal behavior mainly following APAR for both species (Figure 4(A1-A4,D1-D4)). F F60-yield follows the incoming radiation until solar noon, but stay rather relatively high after solar noon (Figure 4(E1-E4)). The PRI shows a much less 
pronounced diurnal behavior for both species (Figure 4(F1-F4)) and remains relatively constant during the course of the day, in part a consequence of the scaled procedures.
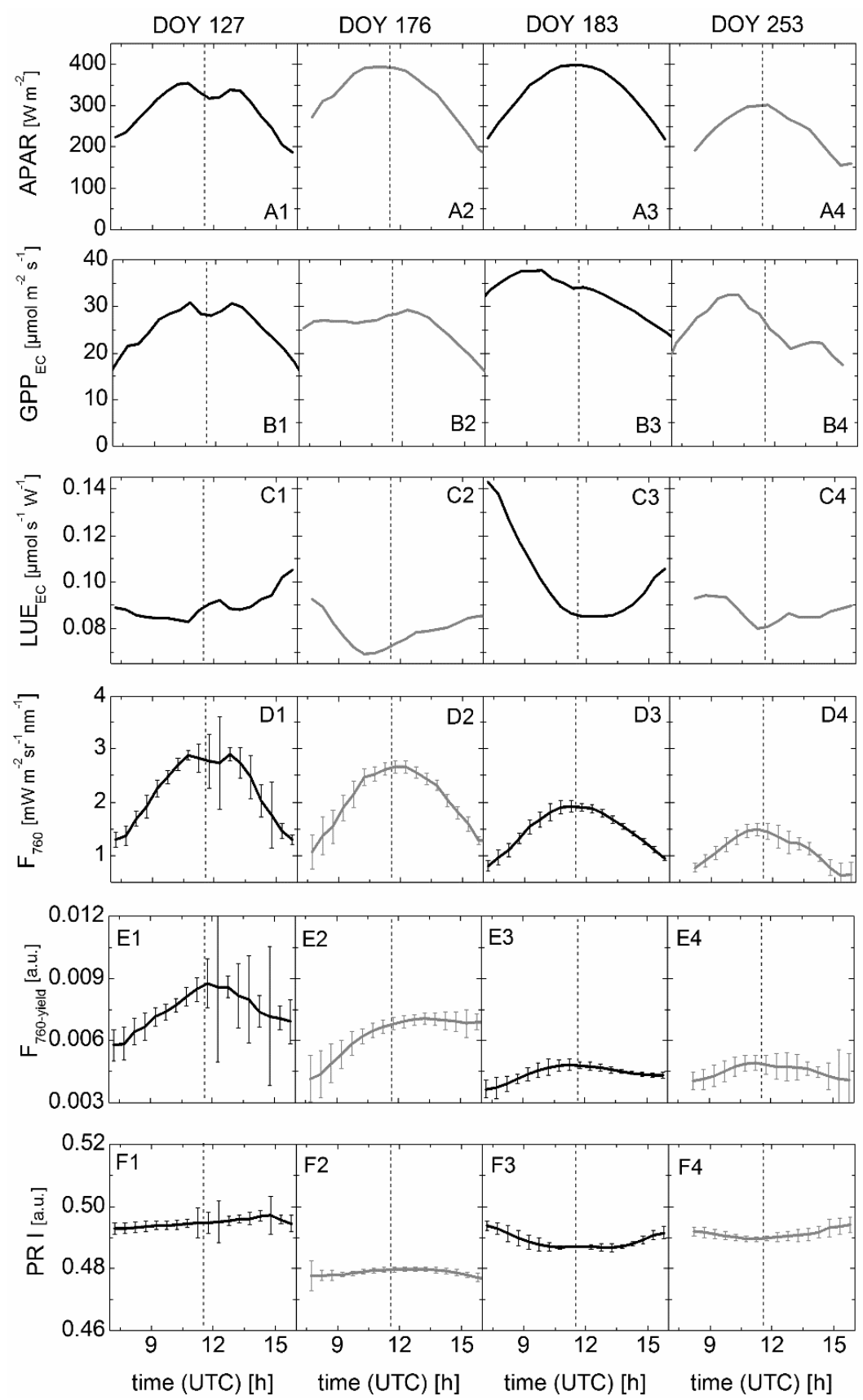

Figure 4. Diurnal behavior of canopy variables measured on the ground in a winter wheat field on DOY 127 and 176 and in a sugar beet field on DOY 183 and 253. Top row (A1-A4): Photosynthetically active radiation absorbed by the canopy (APAR); Second row (B1-B4): Gross primary productivity derived from the eddy covariance (EC) measurements $\left(\mathrm{GPP}_{\mathrm{EC}}\right)$; Third row $(\mathrm{C1}-\mathrm{C} 4)$ : Light-use efficiency of photosynthetic $\mathrm{CO}_{2}$ uptake derived from the EC data (LUEEC); Fourth row (D1-D4): Sun-induced chlorophyll fluorescence $\left(\mathrm{F}_{760}\right)$ obtained from ground-based spectroscopy measurements; Fifth row (E1-E4): Sun-induced chlorophyll fluorescence yield $\left(\mathrm{F}_{760 \text {-yield }}\right)$ obtained from ground-based spectroscopy measurements; Bottom row (F1-F4): Photochemical reflectance index (PRI) obtained from ground-based spectroscopy measurements. Vertical dashed lines indicate the solar noon. Vertical error bars indicate the standard deviation $(n=200$ single measurements within a 30 min time window, rows $\mathbf{D}$ to $\mathbf{F}$ ). 
$\mathrm{GPP}_{\mathrm{EC}}$ showed clear diurnal behavior with winter wheat reaching its maximum near solar noon (Figure 4(B1,B2)) and sugar beet-before solar noon (Figure 4(B3,B4)). GPP $\mathrm{EC}_{\mathrm{C}}$ of sugar beet decreased from DOY 183 to DOY 253, which can partly be explained by a decrease in the incoming radiation towards fall. LUE $E_{\mathrm{EC}}$ generally decreased for both species from morning to noon and increased again in the afternoon (Figure $4(\mathrm{C} 1-\mathrm{C} 4)$ ), with a more pronounced diurnal course in the young sugar beet crop.

Leaf-level measurements of sugar beet showed an increase of maximum stomatal resistance (Figure 5(B3,B4)) and a reduced $\mathrm{CO}_{2}$ uptake rate $\left(\mathrm{A}_{\max }\right.$ in Figure $\left.5(\mathrm{~A} 3, \mathrm{~A} 4)\right)$ in the afternoon, which may indicate stomatal closure. However, stomatal closure was not observed for the single leaf measurements in winter wheat (Figure 5(A1,A2,B1,B2)) Additional measurements of $A_{\max }$ in wheat and sugar beet confirm the observations of the single measurements days (Figure S2 supplementary materials).
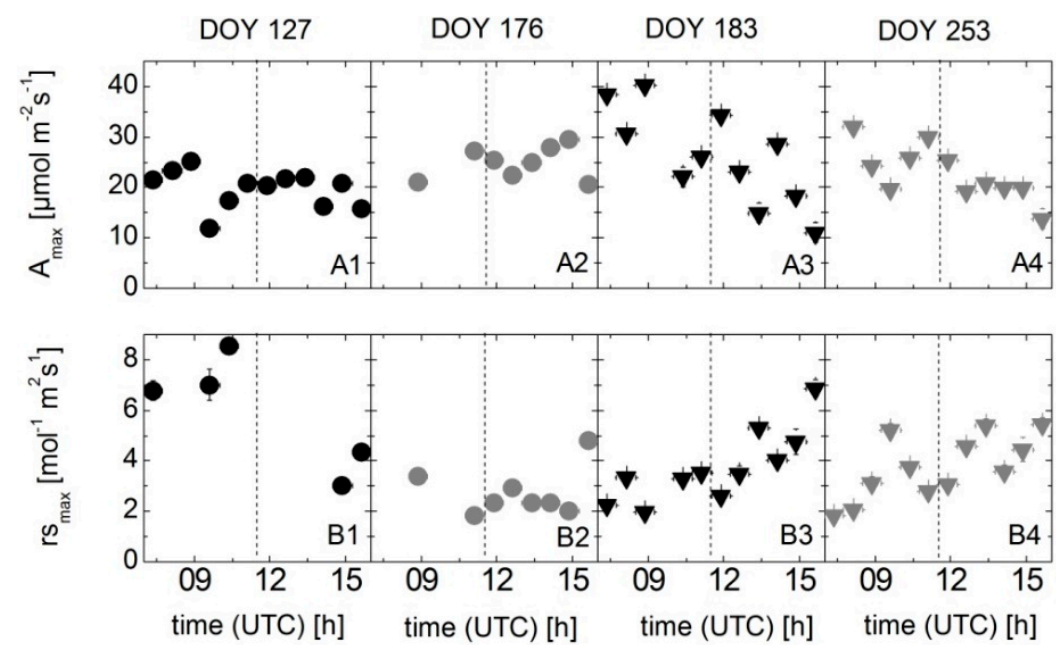

Figure 5. Diurnal behavior of gas exchange parameters derived at saturating light intensities, measured at leaf level for winter wheat (DOY 127, 176) and sugar beet (DOY 183, 253). Circles represent values for winter wheat and triangles values for sugar beet. Top row (A1-A4): Maximum net photosynthetic $\mathrm{CO}_{2}$ uptake rate $\left(A_{\max }\right)$; Bottom row (B1-B4): Maximum stomatal resistance $\left(r s_{\max }\right)$. Vertical error bars indicate uncertainties of the fitting used to determine $A_{\max }$ and $r s_{\max }$. Horizontal error bars indicate the time intervals of measurements. Vertical dashed lines indicate solar noon. See also Figure S2 in supplementary materials for additional measurements at three other days that show a similar diurnal behavior of $A_{\max }$.

\subsection{Correlation between Sun-Induced Fluorescence Yield, Photochemical Reflectance Index, and Photosynthetic} Light-Use Efficiency

We found an overall inverse relationship between $\mathrm{F}_{760}$-yield and LUEE $\mathrm{E}_{\mathrm{EC}}$ for both species (Figure 6(A1-A4)). For sugar beet, the relationship is almost linear (Figure 6(A3,A4)), whereas for winter wheat the relationship between $\mathrm{F}_{760}$-yield and $\mathrm{LUE}_{\mathrm{EC}}$ changed over the day and is described by a hysteresis (Figure 6(A1,A2)). With increasing PAR in the morning, $\mathrm{F}_{760 \text {-yield increased, whereas }}$ $\mathrm{LUE}_{\mathrm{EC}}$ decreased (negative correlation). During midday and high light intensities, $\mathrm{LUE}_{\mathrm{EC}}$ and $\mathrm{F}_{760 \text {-yield }}$ were positively correlated, only in winter wheat. In the afternoon, with decreasing incoming radiation, $\mathrm{LUE}_{\mathrm{EC}}$ and $\mathrm{F}_{760 \text {-yield }}$ again showed a negative correlation for both species. We found no overall consistent relationship between PRI and LUE $E_{\mathrm{EC}}$ for both species (Figure 6(B1-B4). For sugar beet, PRI and $\mathrm{LUE}_{\mathrm{EC}}$ are positive correlated (Figure 6(B3,B4)), however, the correlation on DOY 253 is only weak and not significant (see Table S3 in the supplementary materials). For winter wheat the relationship between PRI and LUE $E_{\mathrm{EC}}$ is not clear. Figure 6(B1,B2) does not show any obvious correlation on both measurement days. However, statistical analyses revealed a slight negative correlation on DOY 176 only (Table S3 supplementary materials). 


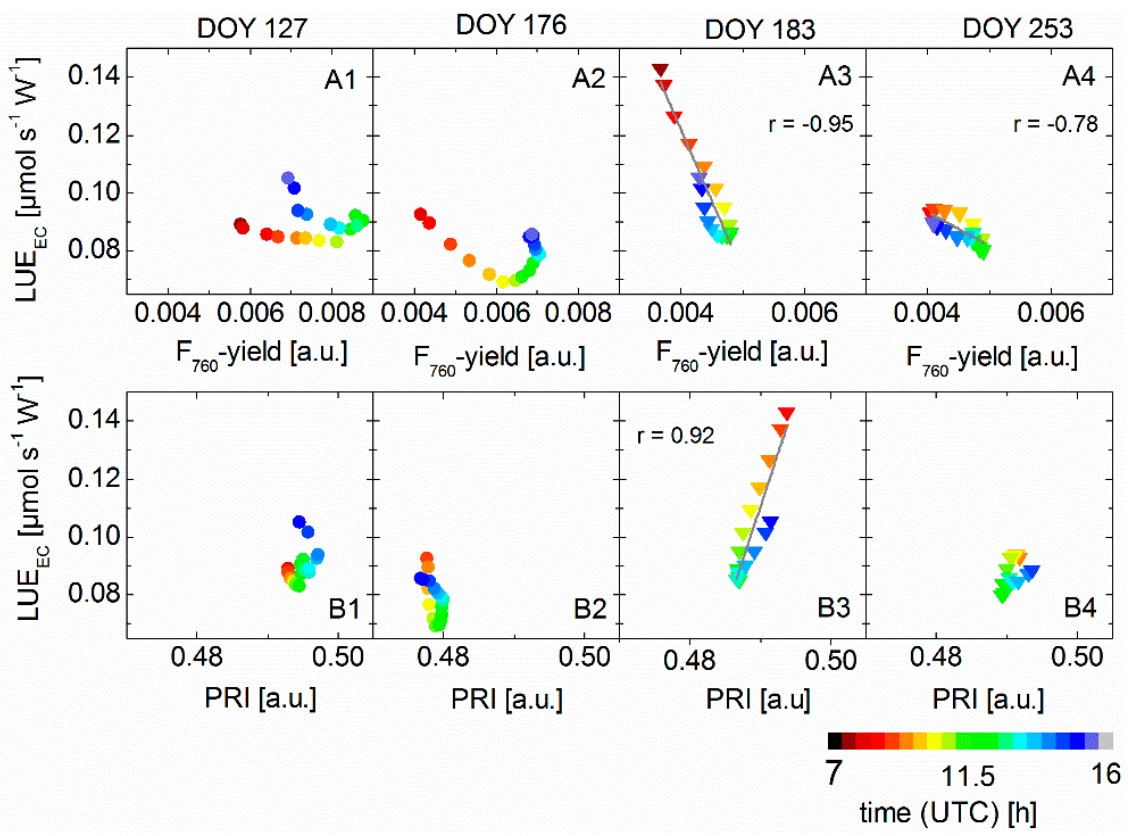

Figure 6. Light-use efficiency derived from eddy covariance (EC) observations (LUEEC) in relation to sun-induced fluorescence yield ( $\left.\mathrm{F}_{760 \text {-yield }}\right)$ and photochemical reflectance index (PRI) obtained from ground-based spectroscopy for winter wheat (DOY 127, 176) and sugar beet (DOY 183, 253). Top row (A1-A4): relationship between light use efficiency $\left(\mathrm{LUE}_{\mathrm{EC}}\right)$ and sun-induced fluorescence yield $\left(\mathrm{F}_{760 \text {-yield }}\right)$. Bottom row (B1-B4): relationship between light use efficiency (LUEEC $)$ and photochemical reflectance index (PRI). The color code indicates the observation time (UTC). Gray lines represent a linear model fitted to the sugar beet data, the goodness of fit is indicated with the correlation coefficient (r). All parameters of the linear model and results of the cross validation are given in Tables S2 and S3 in the supplementary materials.

\subsection{Modeling GPP Using Spectroradiometric Measurements of Sun-Induced Fluorescence and PRI as Dynamic} Input Parameters

Diurnal courses of GPP were calculated according to Equations (10)-(14): using constant values of LUE or by replacing them with $\mathrm{F}_{760}$ and PRI, and using NDVI as a proxy for $f_{\text {APAR }}$. The use of constant LUE values (modeling approaches A and B) did not allow accurate modeling of the asymmetric diurnal course of measured $\mathrm{GPP}_{\mathrm{EC}}$, which exhibited maximum values of carbon assimilation that do not coincide with highest PAR values at solar noon (Figure 7). Incorporating instantaneous $F_{760 \text {-yield }}$ and PRI measurements, however, allowed a substantially improved modeling of GPP diurnals; even the asymmetric $\mathrm{GPP}_{\mathrm{EC}}$ behavior of sugar beet across the day could be partly reproduced (Figure $7(\mathrm{~A} 3, \mathrm{~A} 4)$ ).

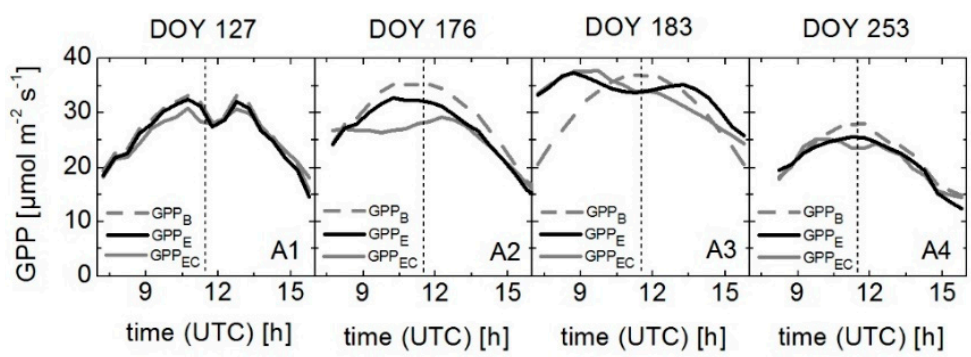

Figure 7. Diurnal behavior of gross primary productivity (GPP) derived from the eddy covariance (EC) method $\left(\mathrm{GPP}_{\mathrm{EC}}\right)$ and GPP calculated using two different approaches $\left(\mathrm{GPP}_{\mathrm{B}}\right.$ and $\left.\mathrm{GPP}_{\mathrm{E}}\right)$ for winter wheat (DOY 127, 176) and for sugar beet (DOY 183, 253). Other model runs $\left(\mathrm{GPP}_{\mathrm{A}}, \mathrm{GPP}_{\mathrm{C}}\right.$ and $\left.\mathrm{GPP}_{\mathrm{D}}\right)$ are also available and results of the improvement are presented in Figure 8. 
We statistically compared the modeling results with the measured $\mathrm{GPP}_{\mathrm{EC}}$ to quantify the improvement for each model per species, by calculating averages of the coefficient of determination $\left(\mathrm{r}^{2}\right)$ and the root mean square error (RMSE), considering all days (Figure 8, Table 1). No significant difference between $\mathrm{GPP}_{\mathrm{A}}$ and $\mathrm{GPP}_{\mathrm{B}}$ was observed for either species, neither in terms of $\mathrm{r}^{2}$ nor in terms of RMSE. This supports the assumption that NDVI can be taken as proxy for $f_{\text {APAR }}$ in both canopies. All approaches using either $\mathrm{F}_{760 \text {-yield }}$ or PRI as approximation of LUE $\left(\mathrm{GPP}_{C}, \mathrm{GPP}_{\mathrm{D}}\right)$ improved the modeling of GPP diurnals (Figure 8 and Table 1). Results were statistically similar for $\mathrm{GPP}_{\mathrm{C}}$ and $\mathrm{GPP}_{\mathrm{D}}$. However, improvement in the diurnal course to match that for GPP $\mathrm{EC}$ was obtained when both PRI and $\mathrm{F}_{760 \text {-yield }}$ were included in the empirical model (modeling approach $\mathrm{E}$ ). In winter wheat, $\mathrm{GPP}_{\mathrm{EC}}$ was mostly driven by the PAR (Figure 7). However, slight improvements were achieved by including PRI or $\mathrm{F}_{760 \text {-yield }}$ in the model. In sugar beet, better model predictions could be observed

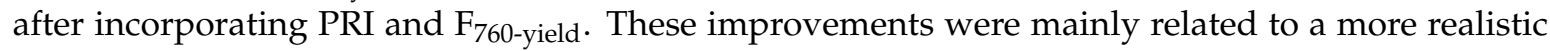
representation of the afternoon decline of GPP in response to a stomatal closure of sugar beet plants. In general, models $\mathrm{GPP}_{\mathrm{D}}$ and $\mathrm{GPP}_{\mathrm{E}}$ performed best for both species (Table 1). For sugar beet (DOY 183 and 253), model GPP $\mathrm{E}_{\mathrm{E}}$, which includes a combination of PRI and $\mathrm{F}_{760}$ as a proxy for LUE, allowed the largest improvements.
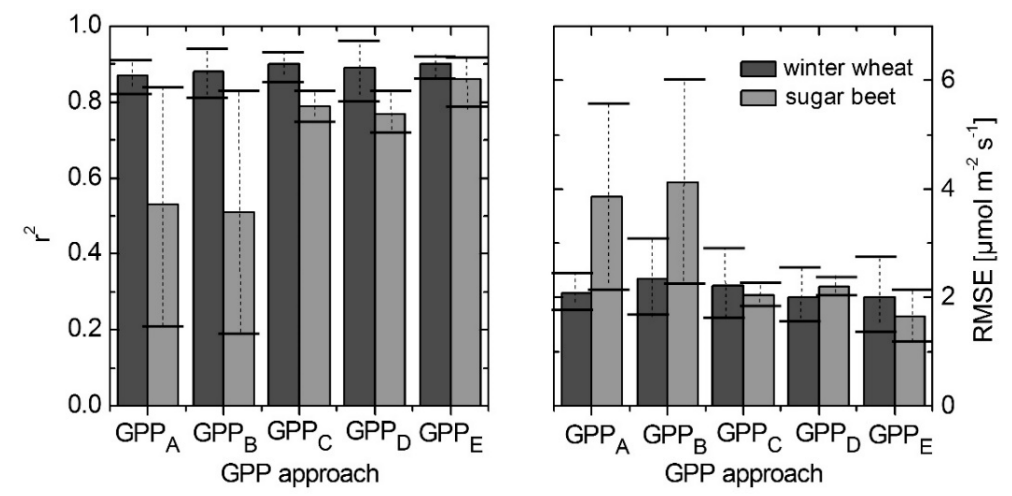

Figure 8. Mean coefficient of determination $\left(\mathrm{r}^{2}\right.$, left) and root mean square error (RMSE, right) $\left[\mu \mathrm{mol} \cdot \mathrm{m}^{-2} \cdot \mathrm{s}^{-1}\right]$ for winter wheat (dark grey) and sugar beet (light gray) for the five different approaches to calculate GPP $\left(\mathrm{GPP}_{\mathrm{A}}-\mathrm{GPP}_{\mathrm{E}}\right)$. Vertical error bars indicate the minimum and maximum values of $\mathrm{r}^{2}$ and RMSE for different observation days.

Table 1. Statistical parameters characterizing the relation between measured $\mathrm{GPP}_{\mathrm{EC}}$ and calculated GPP $\left(\mathrm{GPP}_{\mathrm{A}^{-}} \mathrm{GPP}_{\mathrm{E}}\right)$. The coefficient of determination $\left(\mathrm{r}^{2}\right)$ and the root mean square error (RMSE) $\left[\mu \mathrm{mol} \cdot \mathrm{m}^{-2} \cdot \mathrm{s}^{-1}\right]$ are given. Calculated GPP that matched best at each observation day according to $\mathrm{r}^{2}$ and RMSE are listed in bold.

\begin{tabular}{cccccccccccc}
\hline DOY & Crop & \multicolumn{2}{c}{ GPP $_{\mathbf{A}}$} & \multicolumn{2}{c}{ GPP $_{\mathbf{B}}$} & \multicolumn{2}{c}{ GPP $_{\mathrm{C}}$} & \multicolumn{2}{c}{ GPP $_{\mathbf{D}}$} & \multicolumn{2}{c}{ GPP $_{\mathrm{E}}$} \\
\hline & & $\mathbf{r}^{\mathbf{2}}$ & $\mathbf{R M S E}$ & $\mathbf{r}^{\mathbf{2}}$ & $\mathbf{R M S E}$ & $\mathbf{r}^{\mathbf{2}}$ & $\mathbf{R M S E}$ & $\mathbf{r}^{\mathbf{2}}$ & $\mathbf{R M S E}$ & $\mathbf{r}^{\mathbf{2}}$ & RMSE \\
\hline 127 & Winter wheat & 0.92 & 1.73 & 0.95 & 1.63 & 0.94 & 1.58 & $\mathbf{0 . 9 7}$ & 1.51 & 0.93 & $\mathbf{1 . 3 1}$ \\
176 & Winter wheat & 0.83 & $\mathbf{2 . 4 0}$ & 0.82 & 3.04 & 0.86 & 2.86 & 0.81 & 2.50 & $\mathbf{0 . 8 7}$ & 2.70 \\
183 & Sugar beet & 0.21 & 5.56 & 0.19 & 6.00 & 0.75 & 2.26 & 0.72 & 2.37 & $\mathbf{0 . 7 9}$ & $\mathbf{2 . 1 3}$ \\
253 & Sugar beet & 0.84 & 2.13 & 0.83 & 2.24 & 0.83 & 1.83 & 0.83 & 2.03 & $\mathbf{0 . 9 2}$ & $\mathbf{1 . 1 8}$ \\
\hline
\end{tabular}

\section{Discussion}

We demonstrate that airborne based spectroscopy with medium spectral resolution can serve to retrieve consistent time series of $\mathrm{F}_{760}$ (Figure 4). Our data show significant spatial heterogeneity of $\mathrm{F}_{760}$ between different fields of the same crop, indicating a substantial variation of photosynthetic activity in crops that were expected to be homogeneous (Figures 2 and 3). We show that using measurements of $\mathrm{F}_{760}$ and PRI significantly improves the forward modeling of GPP, in particular if functional down regulation of photosynthetic efficiency occurs. 
The retrieval of fluorescence is challenging. For airborne retrievals, basically three different approaches are currently available: Singular vector decomposition approaches obtain a series of spectral functions based on a set of training data. Singular vectors represent spectral effects of atmospheric absorption and scattering processes as well as surface properties. Recombining these singular vectors facilitates the atmospheric correction and the fluorescence retrieval within one processing step [40-42]. Another approach is based on a rigorous physically based atmospheric correction in combination with a full spectral fitting of the fluorescence signal and is currently being developed [43]. In our study, we used a recently adapted version of the FLD principle [34], which works well for medium resolution spectroscopy data as long as non-vegetated reference targets are abundant in the time series. However, for future applications we expect that the spectral fitting method will provide the most robust and consistent fluorescence retrievals, without need for reference surfaces in the scene. It should be noted that many advances have occurred since 2008 so that if this study were repeated in 2016 it would require different spectrometers and different sampling procedures to incorporate recent knowledge and technologies.

We continued the pioneering work of [20], who introduced a semi-mechanistic framework to use $\mathrm{F}_{760}$ measurements for improved modeling of diurnal courses of GPP. We extended the work with this demonstration study and show that a notable model improvement occurs in particular in the presence of a functional regulation of photosynthesis: leaf level measurements at winter wheat indicate no diurnal regulation, resulting in a high stomatal resistance and a constant photosynthetic capacity during the day. In consequence, there was no significant improvement of GPP predictions by using $\mathrm{F}_{760}$ (Figure 8). In contrast, sugar beet showed a clear stomatal closure in the afternoon and a concomitant reduction of the leaf-level photosynthetic capacity. Thus, GPP models largely improved predictions of GPP in sugar beet when utilizing $\mathrm{F}_{760}$ (Figure 8) on the two observation days. Comparable results were obtained for $\mathrm{F}_{760 \text {-yield }}$ and PRI for both species. It must be noted that only the limited dataset of this demonstration study restricts the generalization of the drawn conclusions. Nevertheless, within the limits of the dataset we interpret this as a clear indication that $\mathrm{F}_{760}$ is indeed related to the functional status of actual photosynthesis as already suggested by $[20,42,44]$.

Potential disturbing effects such as structural changes or changes in the pigment content were expected to be negligible in the course of single days and reflectance anisotropy effects as described by [11] are expected to have similar impacts in the morning and afternoon due to comparable solar illumination angles.

We used a relatively simple empirical modeling approach based on the principles of Monteith's LUE concept. Recent studies theoretically and experimentally demonstrate the close link between $\mathrm{F}_{760}$ and APAR as well as a secondary sensitivity to LUE [45-47]. Our results are in line with these findings and provide further evidence that APAR and LUE can be successfully approximated with $\mathrm{F}_{760}$, allowing an improved modeling of GPP diurnals. However, various effects were discussed causing $\mathrm{F}_{760}$ - GPP relationships to be ecosystem specific [45], eventually hindering a more universal use of $\mathrm{F}_{760}$ to constrain GPP. In fact, there is an ongoing discussion about how sun-induced fluorescence can best be assimilated in existing model formulations to use it to constrain GPP across ecosystems and scales. According to our knowledge only the newest version of the SCOPE model provides an explicit fluorescence interface [48,49], as well as a modified version of the community land model 4 (CLM-4) [50]. Both models facilitate a diagnostic use of sun-induced fluorescence for a GPP assessment across ecosystems and scales. New model formulations and developments are, however, needed to fully exploit the information content inherent in the fluorescence signal (i.e., full emission shape, peak emissions at $687 \mathrm{~nm}$ and $740 \mathrm{~nm}$ ). Such information will soon become frequently available from future satellite sensors (e.g., ESA's TROPOMI onboard Sentinel-5 [51], FLORIS onboard FLEX [52]).

Further, it became clear that not only $\mathrm{F}_{760}$ but also the incorporation of the PRI improved the prediction of GPP. Diurnal changes in PRI were already shown to be related to diurnal adaptation of photosynthesis [53]. $\mathrm{F}_{760}$ is emitted from the core of both photosystems and, thus, is related to the efficiency of photochemical energy separation. The PRI, in contrast, is related to the degree of 
non-photochemical energy dissipation (NPQ). $\mathrm{F}_{760}$ and PRI are often inversely correlated (e.g., [53,54]). However, it cannot be assumed that they are simply or linearly correlated. In our study, the use of a combination of $\mathrm{F}_{760 \text {-yield }}$ and PRI provided the best input to predict diurnal variations in GPP, particularly for the sugar beets with functional limitation of carbon uptake, where NPQ is likely present at a high level of expression (Table 1).

We investigated the spatio-temporal variability of vegetation fluorescence using medium resolution airborne data that were acquired over a large area. We demonstrate a substantial functional variability occurring at two different spatial scales, namely within single fields and between different fields. This indicates that management practices, soil properties or seed material are of considerable importance in determining spatial patterns of vegetation carbon fixation. Again large differences between morning and afternoon measurements of $\mathrm{F}_{760}$ and PRI were observed in sugar beet (Figure 3), which underlines our interpretation of the leaf-level regulation and the functional fingerprint in these two physiological remote sensing parameters.

\section{Conclusions}

We conclude, from the results of this demonstration study, that sun-induced fluorescence provides complementary information compared to commonly used RS based vegetation variables to characterize plant photosynthetic activity. $\mathrm{F}_{760}$ can reliably be derived from medium and high resolution reflectance data and improves our capability to model dynamically occurring limitations in photosynthetic energy conversion. The PRI complements the $\mathrm{F}_{760}$; however, its use is still problematic because of its cross-sensitivity to structural effects [9], pigment pool sizes [10], reflectance anisotropy [11], and illumination effects [11,54]. This study demonstrates the necessity to include the physiological processes underlying the photosynthesis that can be determined with remote sensing approaches as part of calibration and validation campaigns to be conducted in the support of the FLEX satellite mission in the upcoming years using an already existing network such as OPTIMISE (http:/ / optimise.dcs.aber.ac.uk/). In the near future, we expect that retrieval algorithms will become operational that allow quantifying the two fluorescence peak features originating from the two functionally separated photosystems. This will largely boost our ability to mechanistically understand and interpret of limitations in the photosynthetic machinery. Further, the first high resolution imaging spectrometer for fluorescence retrieval (HyPlant) recently became operational and further insights into the spatio-temporal variability of the sun-induced fluorescence signal can be expected [42,44].

Supplementary Materials: The following are available online at www.mdpi.com/2072-4292/8/7/574/s1, Table S1: Parameters characterizing the relation between NDVI and $f_{\text {APAR; }}$ Table S2: Parameters characterizing the relation between $\mathrm{F}_{760 \text {-yield }}$ and $\mathrm{LUE}_{\mathrm{EC}}$; Table S3: Parameters characterizing the relation between PRI and LUE $\mathrm{EC}_{\text {; }}$

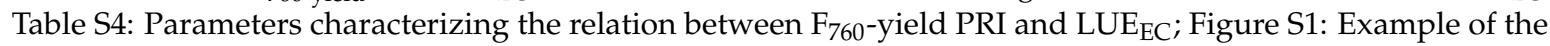
single exponential fit to derive the maximum net photosynthetic $\mathrm{CO}_{2}$ uptake rate $\left(\mathrm{A}_{\max }\right)$ from a light responds curve; Figure S2: Maximum net photosynthetic $\mathrm{CO}_{2}$ uptake rate $\left(\mathrm{A}_{\max }\right)$ of wheat and sugar beet.

Acknowledgments: We gratefully acknowledge financial support provided by the SFB/TR 32 "Patterns in Soil-Vegetation-Atmosphere Systems: Monitoring, Modelling, and Data Assimilation"—subproject D2 (www.tr32.de), funded by the Deutsche Forschungsgemeinschaft (DFG). The authors sincerely thank Marius Schmidt for the measurements and data processing of the Selhausen eddy covariance station. Alexander Damm was supported by a grant of the Swiss University Conference and ETH-Board in frame of the Swiss Earth Observatory Network (SEON) project (www.seon.uzh.ch). Alexander Graf was supported by the German Federal Ministry of Research and Education (BMBF) in the framework of the project IDAS-GHG (Grant 01LN1313A).

Author Contributions: Uwe Rascher conceived the study and designed the experiments. He was PI of the campaigns and organized data acquisition and analysis with the assistance of Anke Schickling, Jan H. Schween, Andreas Wahner and Susanne Crewell. Anke Schickling recorded the ground data and analyzed the data set. Maria Matveeva performed the statistical analysis and wrote with Anke Schickling the manuscript. Alexander Damm developed the fluorescence retrieval algorithm and analyzed the airborne data. Alexander Graf performed the Merken eddy covariance measurements, their processing and the documentation of the eddy covariance measurements.

Conflicts of Interest: The authors declare no conflict of interest. 


\section{References}

1. Le Quéré, C.; Raupach, M.R.; Canadell, J.G.; Marland, G.; Bopp, L.; Ciais, P.; Conway, T.J.; Doney, S.C.; Feely, R.A.; Foster, P.; et al. Trends in the sources and sinks of carbon dioxide. Nat. Geosci. 2009, 2, 831-836. [CrossRef]

2. Xia, J.; Niu, S.; Ciais, P.; Janssens, I.A.; Chen, J.; Ammann, C.; Arain, A.; Blanken, P.D.; Cescatti, A.; Bonal, D.; et al. Joint control of terrestrial gross primary productivity by plant phenology and physiology. Proc. Natl. Acad. Sci. USA 2015, 112, 2788-2793. [CrossRef] [PubMed]

3. Cramer, W.; Kicklighter, D.W.; Bondeau, A.; Moore, B.; Churkina, C.; Nemry, B.; Ruimy, A.; Schloss, A.L. Comparing global models of terrestrial net primary productivity (NPP): Overview and key results. Glob. Chang. Biol. 1999, 5, 1-15. [CrossRef]

4. Monteith, J.L. Solar-radiation and productivity in tropical ecosystems. J. Appl. Ecol. 1972, 9, 747-766. [CrossRef]

5. Monteith, J.L. Climate and efficiency of crop production in Britain. Philos. Trans. R. Soc. Lond. Ser. B Biol. Sci. 1977, 281, 277-294. [CrossRef]

6. Rascher, U.; Nedbal, L. Dynamics of photosynthesis in fluctuating light-Commentary. Curr. Opin. Plant Biol. 2006, 9, 671-678. [CrossRef] [PubMed]

7. Asner, G.P.; Martin, R.E.; Carlson, K.M.; Rascher, U.; Vitousek, P.M. Vegetation-climate interactions among native and invasive species in Hawaiian rainforest. Ecosystems 2006, 6, 1106-1117. [CrossRef]

8. Gamon, J.A.; Peñuelas, J.; Field, C.B. A narrow-waveband spectral index that tracks diurnal changes in photosynthetic efficiency. Remote Sens. Environ. 1992, 41, 35-44. [CrossRef]

9. Barton, C.V.M.; North, P.R.J. Remote sensing of canopy light use efficiency using the photochemical reflectance index-Model and sensitivity analysis. Remote Sens. Environ. 2001, 78, 264-273. [CrossRef]

10. Gamon, J.A.; Berry, J.A. Facultative and constitutive pigment effects on the Photochemical Reflectance Index (PRI) in sun and shade conifer needles. Isr. J. Plant Sci. 2012, 60, 85-95. [CrossRef]

11. Damm, A.; Guanter, L.; Verhoef, W.; Schläpfer, D.; Garbari, S.; Schaepman, M.E. Impact of varying irradiance on vegetation indices and chlorophyll fluorescence derived from spectroscopy data. Remote Sens. Environ. 2015, 156, 202-215. [CrossRef]

12. Cheng, Y.-B.; Middleton, E.M.; Zhang, Q.; Corp, L.A.; Dandois, J.; Kustas, W.P. The photochemical reflectance index from directional cornfield reflectances: Observations and simulations. Remote Sens. Environ. 2012, 124, 444-453. [CrossRef]

13. Garbulsky, M.F.; Penuelas, J.; Gamon, J.; Inoue, Y.; Filella, I. The photochemical reflectance index (PRI) and the remote sensing of leaf, canopy and ecosystem radiation use efficiencies. A review and meta-analysis. Remote Sens. Environ. 2011, 115, 281-297. [CrossRef]

14. Rascher, U.; Agati, G.; Alonso, L.; Cecchi, G.; Champagne, S.; Colombo, R.; Damm, A.; Daumard, F.; de Miguel, E.; Fernandez, G.; et al. CEFLES2: The remote sensing component to quantify photosynthetic efficiency from the leaf to the region by measuring sun-induced fluorescence in the oxygen absorption bands. Biogeosciences 2009, 6, 1181-1198. [CrossRef]

15. Meroni, M.; Rossini, M.; Guanter, L.; Alonso, L.; Rascher, U.; Colombo, R.; Moreno, J. Remote sensing of solar-induced chlorophyll fluorescence: Review of methods and applications. Remote Sens. Environ. 2009, 113, 2037-2051. [CrossRef]

16. Joiner, J.; Yoshida, Y.; Vasilkov, A.P.; Yoshida, Y.; Corp, L.A.; Middleton, E.M. First observations of global and seasonal terrestrial chlorophyll fluorescence from space. Biogeosciences 2011, 8, 637-651. [CrossRef]

17. Frankenberg, C.; Fisher, J.B.; Worden, J.; Badgley, G.; Saatchi, S.S.; Lee, J.-E.; Toon, G.C.; Butz, A.; Jung, M.; Kuze, A.; et al. New global observations of the terrestrial carbon cycle from GOSAT: Patterns of plant fluorescence with gross primary productivity. Geophys. Res. Lett. 2011, 38, L17706. [CrossRef]

18. Guanter, L.; Frankenberg, C.; Dudhia, A.; Lewis, P.E.; Gomez-Dans, J.; Kuze, A.; Suto, H.; Grainger, R.G. Retrieval and global assessment of terrestrial chlorophyll fluorescence from GOSAT space measurements. Remote Sens. Environ. 2012, 121, 236-251.

19. Guanter, L.; Zhang, Y.G.; Jung, M.; Joiner, J.; Voigt, M.; Berry, J.A.; Frankenberg, C.; Huete, A.R.; Zarco-Tejada, P.; Lee, J.E.; et al. Global and time-resolved monitoring of crop photosynthesis with chlorophyll fluorescence. Proc. Natl. Acad. Sci. USA 2014, 111, E1327-E1333. [CrossRef] [PubMed] 
20. Damm, A.; Elbers, J.; Erler, E.; Gioli, B.; Hamdi, K.; Hutjes, R.; Kosvancova, M.; Meroni, M.; Miglietta, F.; Moersch, A.; et al. Remote sensing of sun induced fluorescence to improve modeling of diurnal courses of gross primary production (GPP). Glob. Chang. Biol. 2010, 16, 171-186. [CrossRef]

21. Cheng, Y.-B.; Middleton, E.M.; Zhang, Q.; Huemmrich, K.F.; Campbell, P.K.E.; Corp, L.A.; Cook, B.D.; Kustas, W.P.; Daughtry, C.S. Integrating solar induced fluorescence and the photochemical reflectance index for estimating gross primary production in a cornfield. Remote Sens. 2013, 12, 6857-6879. [CrossRef]

22. Rossini, M.; Meroni, M.; Migliavacca, M.; Manca, G.; Cogliati, S.; Busetto, L.; Picchi, V.; Cescatti, A.; Seufert, G.; Colombo, R. High resolution field spectroscopy measurements for estimating gross ecosystem production in a rice field. Agric. For. Meteorol. 2010, 150, 1283-1296. [CrossRef]

23. Rossini, M.; Cogliati, S.; Meroni, M.; Migliavacca, M.; Galvagno, M.; Busetto, L.; Cremonese, E.; Julitta, T.; Siniscalco, C.; di Cella, U.; et al. Remote sensing-based estimation of gross primary production in a subalpine grassland. Biogeosciences 2012, 9, 2565-2584. [CrossRef]

24. Farquhar, G.D.; Sharkey, T.D. Stomatal conductance and photosynthesis. Annu. Rev. Plant Physiol. Plant Mol. Biol. 1982, 33, 317-345. [CrossRef]

25. Hall, A.E. Mathematical models of plant water loss and plant water relations. In Encyclopedia of Plant Physiology; Physiological Plant Ecology II; Lange, O.L., Nobel, P.S., Osmond, C.B., Ziegler, H., Eds.; Springer-Verlag: Berlin/Heidelberg, Germany; New York, NY, USA, 1982; pp. 231-261.

26. Swinbank, W.C. The measurement of vertical transfer of heat and water vapor by eddies in the lower atmosphere. J. Meteorol. 1951, 8, 135-145. [CrossRef]

27. Mauder, M.; Foken, T. Documentation and Instruction Manual of the Eddy Covariance Software Package TK2; Department of Micrometeorol, University of Bayreuth: Bayreuth, Germany, 2004.

28. Van Dijk, A.; Moene, A.F.; de Bruin, H.A.R. The Principle of Surface Flux Physics: Theory, Practice and Description of the ECPACK Library; Internal Rep. 2004/1; Meteorology and Air Quality Group, Wageningen University: Wageningen, The Netherlands, 2004.

29. Schmidt, M.; Reichenau, T.G.; Fiener, P.; Schneider, K. The carbon budget of a winter wheat field: An eddy covariance analysis of seasonal and inter-annual variability. Agric. For. Meteorol. 2012, 165, 114-126. [CrossRef]

30. Graf, A.; Prolingheuer, N.; Schickling, A.; Schmidt, M.; Schneider, K.; Schuttemeyer, D.; Herbst, M.; Huisman, J.A.; Weihermuller, L.; Scharnagl, B.; et al. Temporal downscaling of soil carbon dioxide efflux measurements based on time-stable spatial patterns. Vadose Zone J. 2011, 10, 239-251. [CrossRef]

31. Reichstein, M.; Falge, E.; Baldocchi, D.; Papale, D.; Aubinet, M.; Berbigier, P.; Bernhofer, C.; Buchmann, N.; Gilmanov, T.; Granier, A.; et al. On the separation of net ecosystem exchange into assimilation and ecosystem respiration: Review and improved algorithm. Glob. Chang. Biol. 2005, 11, 1424-1439. [CrossRef]

32. Neininger, B.; Fuchs, W.; Baeumle, M.; Volz-Thomas, A.; Prévôt, A.S.H.; Dommen, J. A small aircraft for more than just ozone: Metair's 'Dimona' after ten years of evolving development. In Proceedings of the 11th Symposium on Meteorological Observations and Instrumentation, Albuquerque, NM, USA, 14-19 January 2001.

33. Berk, A.; Anderson, G.P.; Acharya, P.K.; Bernstein, L.S.; Muratov, L.; Lee, J.; Fox, M.; Adler-Golden, S.M.; Chetwynd, J.H.; Hoke, M.L.; et al. MODTRAN5: A reformulated atmospheric band model with auxiliary species and practical multiple scattering options. Proc. Soc. Photo-Opt. Instrum. Eng. 2005, 5655, 662-667.

34. Damm, A.; Guanter, L.; Laurent, V.C.E.; Schaepman, M.E.; Schickling, A.; Rascher, U. FLD-based retrieval of sun-induced chlorophyll fluorescence from medium spectral resolution airborne spectroscopy data. Remote Sens. Environ. 2014, 147, 256-266. [CrossRef]

35. Maier, S.W.; Günther, K.P.; Stellmes, M. Sun-induced fluorescence: A new tool for precision farming. In Digital Imaging and Spectral Techniques: Applications to Precision Agriculture and Crop Physiology; McDonald, M., Schepers, J., Tartly, L., van Toai, T., Major, D., Eds.; ASA Special Publication: Boston, MA, USA, 2003; pp. 209-222.

36. Gitelson, A.A.; Gamon, J.A. The need for a common basis for defining light-use efficiency: Implications for productivity estimation. Remote Sens. Environ. 2015, 156, 196-201. [CrossRef]

37. Rouse, J.W., Jr.; Haas, R.H.; Schell, J.A.; Deering, D.W. Monitoring vegetation systems in the Great Plains with ERTS. Third ERTS Symposium; NASA SP-351; NASA: Washington, DC, USA, 1973; pp. 309-317.

38. Tucker, C.J. Red and photographic infrared linear combinations for monitoring vegetation. Remote Sens. Environ. 1979, 8, 127-150. [CrossRef] 
39. Myneni, R.B.; Williams, D.L. On the relationship between FAPAR and NDVI. Remote Sens. Environ. 1994, 49, 200-211. [CrossRef]

40. Guanter, L.; Rossini, M.; Colombo, R.; Meroni, M.; Frankenberg, C.; Lee, J.-E.; Joiner, J. Using field spectroscopy to assess the potential of statistical approaches for the retrieval of sun-induced chlorophyll fluorescence from ground and space. Remote Sens. Environ. 2013, 133, 52-61. [CrossRef]

41. Joiner, J.; Guanter, L.; Lindstrot, R.; Voigt, M.; Vasilkov, A.P.; Middleton, E.M.; Huemmrich, K.F.; Yoshida, Y.; Frankenberg, C. Global monitoring of terrestrial chlorophyll fluorescence from moderate spectral resolution near-infrared satellite measurements: Methodology, simulations, and application to GOME-2. Atmos. Meas. Tech. 2013, 6, 2803-2823. [CrossRef]

42. Rossini, M.; Nedbal, L.; Guanter, L.; Ač, A.; Alonso, L.; Burkart, A.; Cogliati, S.; Colombo, R.; Damm, A.; Drusch, M.; et al. Red and far red Sun-induced chlorophyll fluorescence as a measure of plant photosynthesis. Geophys. Res. Lett. 2015, 42. [CrossRef]

43. Sabater, N.; Alonso, L.; Vicent, J.; Cogliati, S.; Verrelst, J.; Moreno, J. A fluorescence retrieval method for the FLEX Sentinel-3 tandem mission. In Proceedings of the Workshop on Hyperspectral Imaging and Signal Processing: Evolution in Remote Sensing (WHISPERS), Lausanne, Switzerland, 24-27 June 2014.

44. Rascher, U.; Alonso, L.; Burkart, A.; Cilia, C.; Cogliati, S.; Colombo, R.; Damm, A.; Drusch, M.; Guanter, L.; Hanus, J.; et al. Sun-induced fluorescence-A new probe of photosynthesis: First maps from the imaging spectrometer HyPlant. Glob. Chang. Biol. 2015, 21, 4673-4684. [CrossRef] [PubMed]

45. Damm, A.; Guanter, L.; Paul-Limoges, E.; Van der Tol, C.; Hueni, A.; Buchmann, N.; Eugster, W.; Ammann, C.; Schaepman, M.E. Far-red sun-induced chlorophyll fluorescence shows ecosystem-specific relationships to gross primary production: An assessment based on observational and modeling approaches. Remote Sens. Environ. 2015, 166, 91-105. [CrossRef]

46. Verrelst, J.; Rivera, J.P.; Van der Tol, C.; Magnani, F.; Mohammed, G.; Moreno, J. Global sensitivity analysis of the SCOPE model: What drives simulated canopy-leaving sun-induced fluorescence? Remote Sens. Environ. 2015, 166, 8-21. [CrossRef]

47. Van der Tol, C.; Berry, J.A.; Campbell, P.K.E.; Rascher, U. Models of fluorescence and photosynthesis for interpreting measurements of solar-induced chlorophyll fluorescence. J. Geophys. Res. Biogeosci. 2014, 119, 2312-2327. [CrossRef]

48. Van der Tol, C.; Verhoef, W.; Rosema, A. A model for chlorophyll fluorescence and photosynthesis at leaf scale. Agricult. For. Meteorol. 2009, 149, 96-105. [CrossRef]

49. Zhang, Y.; Guanter, L.; Berry, J.A.; Joiner, J.; van der Tol, C.; Huete, A.; Gitelson, A.; Voigt, M.; Koehler, P. Estimation of vegetation photosynthetic capacity from space-based measurements of chlorophyll fluorescence for terrestrial biosphere models. Glob. Chang. Biol. 2014, 20, 3727-3742. [CrossRef] [PubMed]

50. Lee, J.E.; Berry, J.A.; Van der Tol, C.; Yang, X.; Guanter, L.; Damm, A.; Baker, I.; Frankenberg, C. Simulations of chlorophyll fluorescence incorporated into the Community Land Model version 4. Glob. Chang. Biol. 2015, 21, 3469-3477. [CrossRef] [PubMed]

51. Guanter, L.; Aben, I.; Tol, P.; Krijger, J.M.; Hollstein, A.; Koehler, P.; Damm, A.; Joiner, J.; Frankenberg, C.; Landgraf, J. Potential of the TROPOspheric Monitoring Instrument (TROPOMI) onboard the Sentinel-5 Precursor for the monitoring of terrestrial chlorophyll fluorescence. Atmos. Meas. Tech. 2015, 8, 1337-1352. [CrossRef]

52. Kraft, S.; Bézy, J.L.; Del Bello, U.; Berlich, R.; Drusch, M.; Franco, R.; Gabriele, A.; Harnisch, B.; Meynart, R.; Silvestrin, P. FLORIS: Phase A status of the fluorescence imaging spectrometer of the Earth Explorer mission candidate FLEX. Proc. SPIE 2013, 8889. [CrossRef]

53. Nichol, C.J.; Rascher, U.; Matsubara, S.; Osmond, C.B. Assessing photosynthetic efficiency in an experimental mangrove canopy using remote sensing and chlorophyll fluorescence. Trees Struct. Funct. 2006, 20, 9-15. [CrossRef]

54. Mottus, M.; Takala, T.L.H.; Stenberg, P.; Knyazikhin, Y.; Yang, B.; Nilson, T. Diffuse sky radiation influences the relationship between canopy PRI and shadow fraction. ISPRS J. Photogramm. Remote Sens. 2015, 105, 54-60. [CrossRef]

(C) 2016 by the authors; licensee MDPI, Basel, Switzerland. This article is an open access article distributed under the terms and conditions of the Creative Commons Attribution (CC-BY) license (http://creativecommons.org/licenses/by/4.0/). 